\title{
Temporal and spatial expression of cuticular proteins of Anopheles gambiae implicated in insecticide resistance or differentiation of $M / S$ incipient species
}

Laura Vannini, Tyler W Reed and Judith H Willis ${ }^{*}$

\begin{abstract}
Background: Published data revealed that two of the 243 structural cuticular proteins of Anopheles gambiae, CPLCG3 and CPLCG4, are implicated in insecticide resistance and a third, CPF3, has far higher transcript levels in M than in $\mathrm{S}$ incipient species. We studied the distribution of transcripts for these three genes in the tissues of An. gambiae and the location of the proteins in the cuticle itself to gain information about how these cuticular proteins contribute to their important roles. Our data are consistent with CPLCG3/4 contributing to a thicker cuticle thus slowing penetration of insecticides and CPF3 possibly having a role in the greater desiccation tolerance of the M form.
\end{abstract}

Methods: Using RT-qPCR, we established the temporal expression of the genes and by in situ hybridization we revealed the main tissues where their mRNAs are found. Electron microscopy immunolocalization, using secondary antibodies labeled with colloidal gold, allowed us to localize these proteins within different regions of the cuticle.

Results: The temporal expression of these genes overlaps, albeit with higher levels of transcripts from CPF3 in pharate adults and both CPLCG3 and CPLCG4 are higher in animals immediately after adult eclosion. The main location of mRNAs for all three genes is in appendages and genitalia. In contrast, the location of their proteins within the cuticle is completely different. CPF3 is found exclusively in exocuticle and CPLCG3/4 is restricted to the endocuticle. The other CPF gene expressed at the same times, CPF4, in addition to appendages, has message in pharate adult sclerites.

Conclusions: The temporal and spatial differences in transcript abundance and protein localization help to account for An. gambiae devoting about $2 \%$ of its protein coding genes to structural cuticular proteins. The location of CPLCG3/4 in the endocuticle may contribute to the thickness of the cuticle, one of the recently appreciated components of insecticide resistance, while the location of CPF3 might be related to the greater desiccation resistance of the $\mathrm{M}$ form.

Keywords: Cuticle, Incipient species, Insecticide resistance, TEM immunolocalization, In situ hybridization

\footnotetext{
*Correspondence: jhwillis@uga.edu

Department of Cellular Biology, University of Georgia, 724 Biological Science Building, 30602, Athens, GA, USA
} 


\section{Background}

Structural cuticular proteins (CPs), chitin and lipids are the major components of the insect cuticle, the exoskeleton, as well as the cuticle that lines some internal structures such as the foregut, hindgut, tracheal system and apodemes. The 243 CPs that have been annotated for Anopheles gambiae comprise close to $2 \%$ of all its protein coding genes. They have been classified into a dozen distinct protein families [1,2]. Sequence domains, homology models and experimental work revealed that members of some CP families contribute to the cuticle by binding chitin; the function of others is not known. Three CPs deserve particular attention because of reported differential expression in adults in important comparisons: AgamCPF3, AgamCPLCG3 and AgamCPLCG4. Hereafter, since we will only be discussing CPs from $A n$. gambiae, the Agam prefix will not be used. These genes belong to two different CP families. The CPF family has four members, two of which (CPF3 and CPF4) are only expressed in pharate adults and adults [3]. (The pharate stage begins when the epidermis has retracted from the old cuticle and has started forming the new cuticle of the next stage.) CPF1 and CPF2 are primarily expressed in larvae and pharate pupae [3]. The CPLCG3 family has 27 members with different members expressed at different times during development [4].

$C P F 3$ has the greatest difference in mRNA levels of transcripts in $\mathrm{M}$ and $\mathrm{S}$ incipient species of An. gambiae based on microarray data and confirmed with RT-qPCR on 3-dold virgin females [5]. These incipient species are forms that only hybridize in a limited region of their range [6]. Of the five genes that were selected for RT-qPCR analysis, CPF3 was the only one with more abundant transcripts in $\mathrm{M}$ than in $\mathrm{S}$, and the difference first found in laboratory strains was confirmed with three distinct natural populations. In these, the difference was only about 3-fold compared to the 27-fold difference in the laboratory strains [5]. Recombinant CPF3 does not bind chitin [3], and a homology model shows that the Drosophila pheromone 7,11-HD (7(Z), 11(Z)-heptacosadiene) would fit its binding pocket [7]. This information led to the suggestion that CPF3 might be localized in the epicuticle where it could present a contact pheromone [5,7].

CPLCG3 and the very similar CPLCG4 (Figure 1B, Additional file 1) have been implicated in insecticide resistance in two species of Anopheles, because they are among the five genes that show over two-fold higher transcript levels in pyrethroid-resistant compared to pyrethroid-sensitive mosquitoes $[8,9]$. (CP gene names used in those papers were not the definitive ones; they are correct in [10]).

Our published studies with RT-qPCR showed that CPF3 has significant expression first seen in pharate adults and persisting into young adults [3]. CPLCG3 and
CPLCG4 also have highest transcript levels at those times, although the levels in young adults are higher than in pharate pupae [4]. Here we report that CPLCG3/ 4 are also similar to $C P F 3$ in the tissues in which transcripts are found, even though they have been implicated in serving distinct roles in Anopheles. The amino acid sequence of CPF3 is not at all similar to CPLCG3 or CPLCG4 (Figure 1A, B). We also examined CPF4, while not implicated in insecticide resistance or $\mathrm{M} / \mathrm{S}$ differences, it has sequence regions (Figure 1C) and temporal patterns of expression similar to that of CPF3, unlike the other two members of the CPF family that have transcripts primarily in pharate and young pupae [3].

While data are accumulating on the spatial distribution of individual CPs across the insect body, there is little information on localization within the cuticle itself. Electron microscopic (EM) immunolocalization has been carried out, but the proteins against which the antibodies, both polyclonal and monoclonal, had been raised were either extracts of the whole cuticle or isolated electrophoretic bands without sequence information (reviewed in [2]). We have begun to remedy this deficiency by using secondary antibodies, labeled with colloidal gold, to detect antibodies raised against specific cuticular proteins. Our focus has been on CPF3 and CPLCG3 and CPLCG4 given the importance of these specific CPs. First, we confirmed the temporal expression patterns of the selected CPs with RT-qPCR and then learned their spatial localization in tissues via in situ hybridization. Finally, we examined their localization in the cuticle itself using immunolocalization on EM sections.

The data we obtained provide insight into the precise roles these proteins may serve, as well as why An. gambiae devotes so many genes to structural cuticular proteins.

\section{Methods \\ Mosquito rearing}

The colony of $A n$. gambiae (G3 strain, reported to be of the $\mathrm{S}$ form) was maintained at $27^{\circ} \mathrm{C}$ in a $14 / 10 \mathrm{hL} / \mathrm{D}$ photoperiod (except for those used for Additional file 2 where conditions are given in the legend). Larvae were fed ground Koi food (Foster and Smith Aquatics), and adults had access to an $8 \%$ fructose solution. To obtain developmentally synchronized animals, pupae were collected at hourly intervals, separated by sex and maintained in small groups until they reached the desired age. Adults were collected on the morning after emergence (d 0) and kept in cages in a humidified insectary until used.

\section{In situ hybridization}

In situ hybridization was carried out on $4 \mu \mathrm{m}$ sections of paraformaldehyde-treated mosquitoes processed by the Histology Laboratory at the University of Georgia, College of Veterinary Medicine. The original probe for CPLCG3 is 


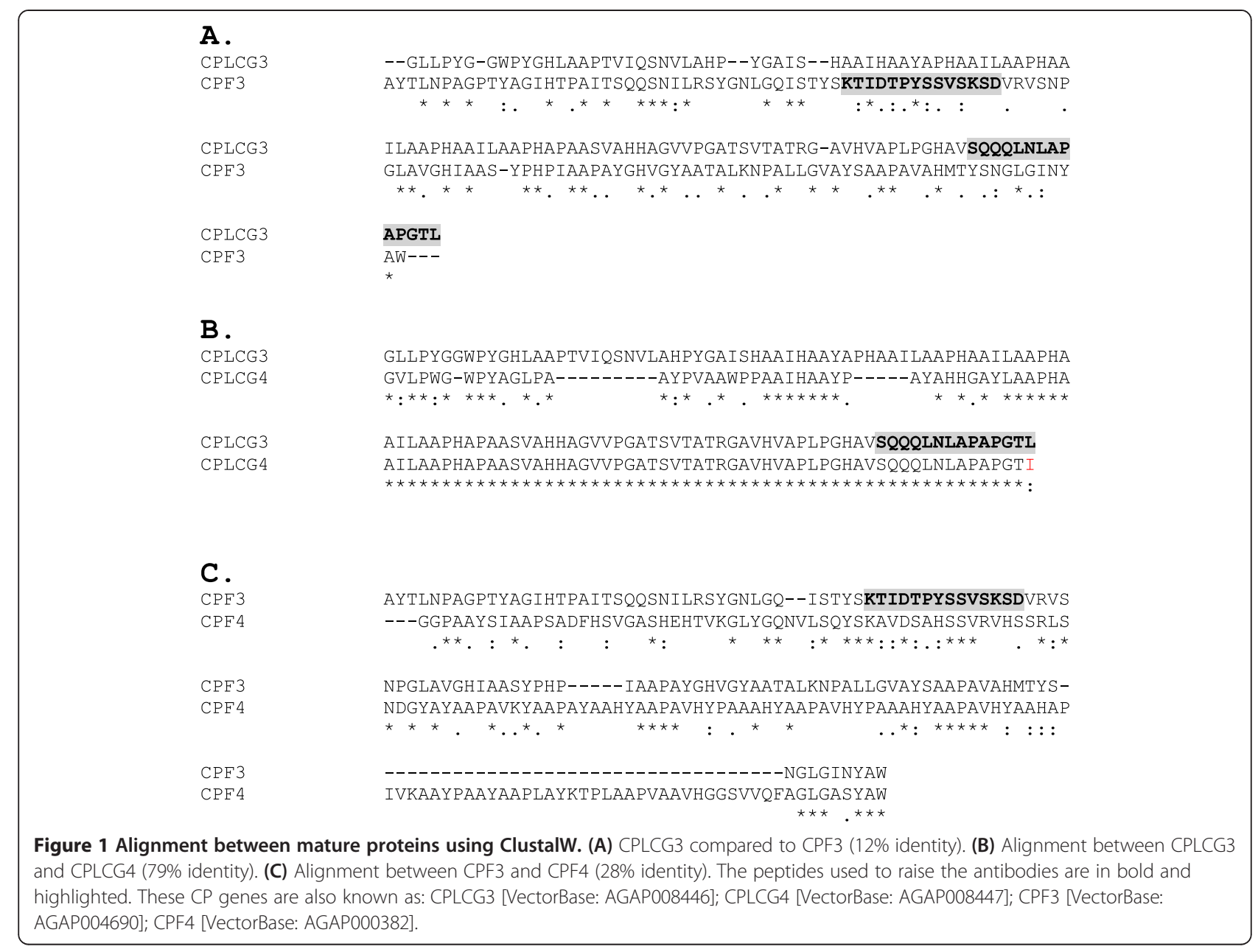

likely to hybridize to CPLCG4, so we designed additional probes in the 3'UTR for each of these genes (see Additional file 1B). No differences were seen in hybridization patterns among these three probes. Probes for CPF3 and CPF4 should be unique (see Additional file 1A). Details on probe construction are in [11]. Probes were labeled with dig (digoxigenin) and visualized after a 2-48 h exposure to NBT (nitro-blue tetrazolium chloride) and BCIP (5-bromo-4-chloro-3' - indolyphosphate p-toluidine). The procedure followed was a slightly simplified version of an EXIQON protocol (http://www. exiqon.com/ls/documents/scientific/edc-based-ish-protocol. pdf) and is described in detail in [11]. We carried out a limited number of hybridizations with sense probes, and found no hybridization. Also, treatment of sections with RNase prior to probe hybridization abolished hybridization to tissue but not the artifactual hybridization to the lens and cast pupal cuticle [11].

\section{RT-qPCR}

We added some additional data to that already published $[3,4]$ following their procedures with primers described in those papers that had been checked for efficiency and verified to amplify only a single gene (see Additional file 3). We used Bio-Rad's MyiQ Real-Time PCR Detection System. All reactions were carried out in triplicate (technical replicates) in a $20 \mu$ reaction containing $5 \mu \mathrm{l}$ of $1 / 100$ diluted cDNAs (equivalent to starting with 7.5ng of total RNA), $250 \mathrm{nM}$ of each primer, and $10 \mu \mathrm{l}$ iQ SYBR ${ }^{\circ}$ Green Supermix (Bio-Rad). PCR conditions were $95^{\circ} \mathrm{C}$ for $3 \mathrm{~min}$ followed by 40 cycles of $95^{\circ} \mathrm{C}$ for $15 \mathrm{~s}$ and $57^{\circ} \mathrm{C}$ for $1 \mathrm{~min}$. We used 5 biological replicates (groups of three animals or three parts) for cDNA preparations. Data were normalized to RpS7 [VectorBase: AGAP010592]. Different conditions and the Bio-Rad's CFX Connect Real Time System were used for Additional file 2 and are described in the legend.

\section{Antibody production}

Antigenic peptides were identified in our laboratory using Abie Pro 3.0 (www.changbioscience.com/abie/abie.html). Peptide synthesis and polyclonal antibody production were carried out by GenScript. The colloidal-gold conjugated 


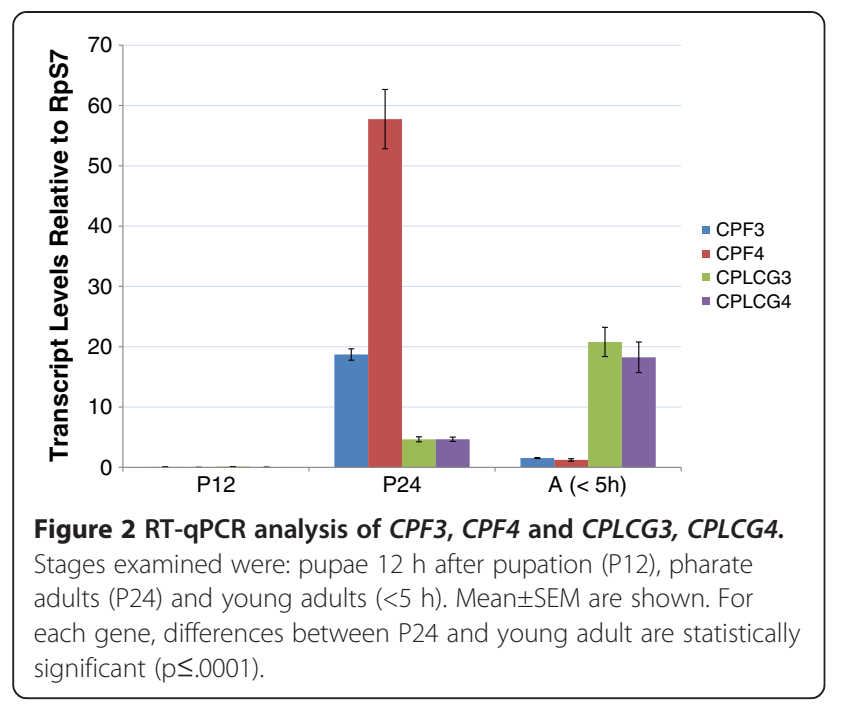

secondary antibodies (Sigma) were $10 \mathrm{~nm}$ goat-antimouse and $5 \mathrm{~nm}$ goat-anti-rabbit.

The peptide against which the rabbit antibodies were raised for CPLCG3 differs only in the last amino acid from CPLCG4 (L in CPLCG3, I in CPLCG4) (Figure 1B). Hence we assume it is detecting both proteins. The peptide used for CPF3 (Figure 1A, C) was unique for that protein and the antibody was raised in mice.

It is unlikely that the antibodies will react with other cuticular proteins based on sequence differences or because the corresponding transcript is absent at the time the proteins would be secreted. The one exception is CPLCG5 that might be detected by the CPLCG3/4 antibody, although its single aa difference is inside the peptide. In situ hybridization revealed that it is expressed in the same tissues as CPLCG3 and CPLCG4 [11]. Details
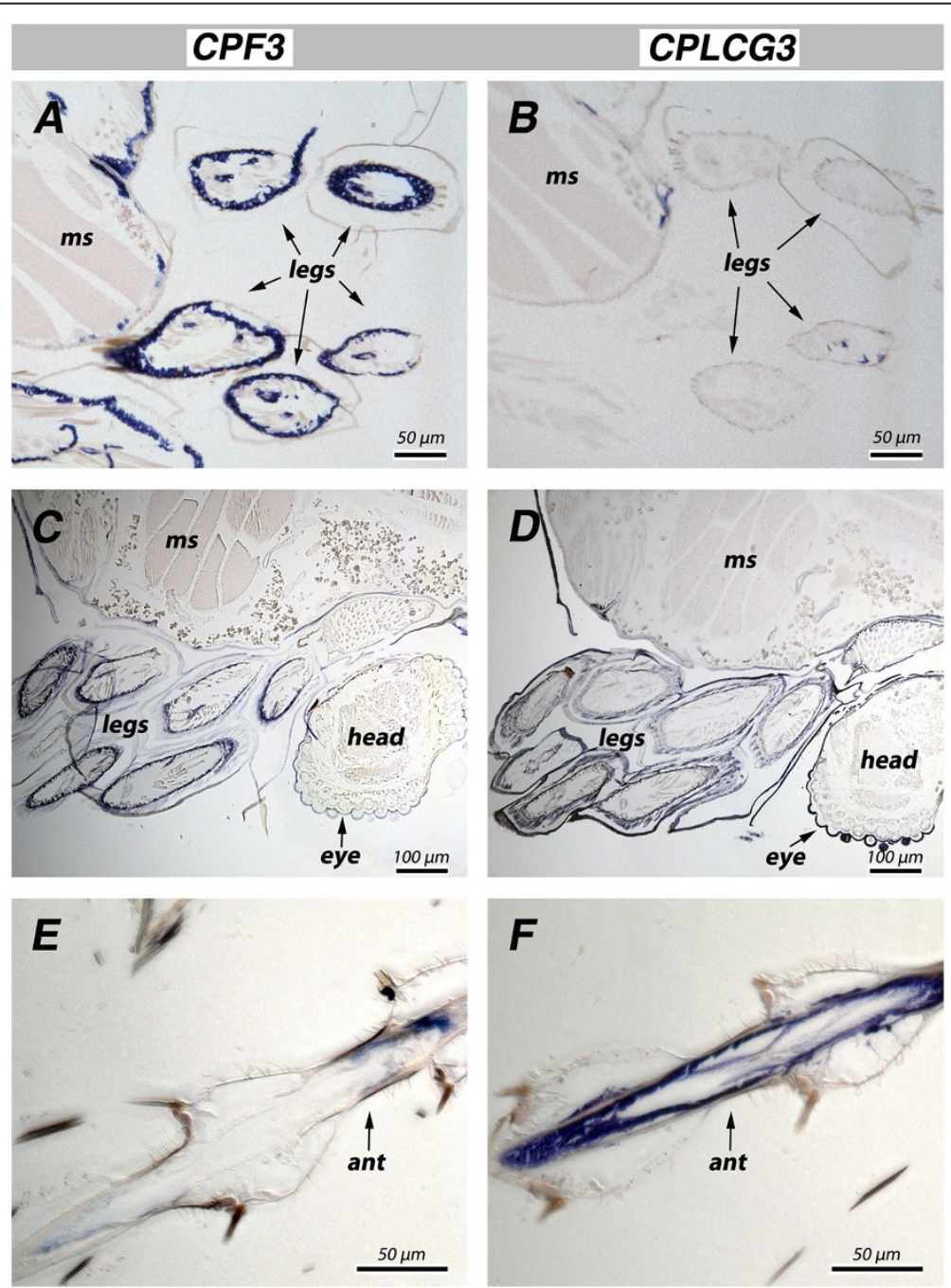

Figure 3 In situ hybridization to appendages of animals of different ages. Most common is greater hybridization for CPF3 than CPLCG3 in P24 (A, B). But occasionally there is similar hybridization of both at P24 (C, D). After eclosion, CPLCG3 is generally stronger in appendages than CPF3, here the antenna of a young adult male, 17-19 h post-eclosion (E, F). ms, muscle; ant, antenna. 
on sequence and expression of potential off-target sequences are in Additional file 4.

\section{Western blots}

Proteins from homogenized whole bodies of mosquitoes (8-d-old) and legs (3-d-old) were extracted in 8M urea, $0.1 \mathrm{M} \mathrm{NaCl}, 0.01 \mathrm{M}$ Tris, $\mathrm{pH} 8.0$, with protease inhibitors (cOmplete, Mini, Roche). Proteins were separated on 4$20 \%$ SDS-PAGE (Bio-Rad) with a Tris-glycine running buffer (2M glycine, $0.25 \mathrm{mM}$ Tris, 1\% SDS) and transferred to polyvinylidene fluoride (PVDF) (Millipore) filters. Filters were blocked with $3 \%$ bovine serum albumin (BSA) in PBST (PBS+0.1\% Tween-20) for $30 \mathrm{~min}$ at room temperature and then incubated with anti-CPF3 $(1: 1,000$ dilution) or anti-CPLCG3/4 (1:30,000 dilution) antibodies in PBST-1\% BSA for $1 \mathrm{~h}$ at room temperature. After four washes with PBST (15 min at room temperature), filters were incubated with anti-mouse or anti-rabbit secondary antibodies that were conjugated to peroxidase at a dilution of 1:20,000 in PBST-1\% BSA for $30 \mathrm{~min}$ at room temperature. Finally, filters were developed with the Western blot Chemiluminescence Reagent Plus Kit (Renaissance) and exposed to X-ray films. As controls, blots were processed in the same way without the primary antibody incubation step. Anti-CPF3 was used with proteins extracted from legs because of the unexplained high background that this antibody showed on proteins extracted from the whole body.

\section{Electron microscopy}

The legs of pharate adults ( $24 \mathrm{~h}$ after pupation, a few hours before eclosion) and 1-d-old and 8-d-old adults were dissected. The fixation, dehydration and embedding steps were performed following [12], introducing some modifications for better integrity of mosquito cuticle. Tissues were fixed in $4 \%$ formaldehyde, $0.3 \%$ glutaraldehyde $+4 \%$ sucrose in phosphate buffer $1 \mathrm{X}$ (PBS) (pH7.4) overnight at $4^{\circ} \mathrm{C}$. Samples were rinsed three times in $\mathrm{PBS}+4 \%$ sucrose $(5 \mathrm{~min})$. All the subsequent steps were performed with continuous shaking at room temperature. The samples were dehydrated in a graded ethanol series: $30 \%$ ethanol-4\% sucrose, 50\%, 70\% and 95\% ethanol (10 min, each). Samples were infiltrated in 1:1 (v:v) and 1:2 (v:v) 95\% ethanol:LR White resin (Electron Microscopy Sciences) and then kept in pure LR White ( $2 \mathrm{~h}$, each), followed by an overnight change and a final change $(2 \mathrm{~h})$ of the resin. Samples were embedded in polyethylene capsules (that had been dried at $50^{\circ} \mathrm{C}$ ) and covered with fresh resin. We used bottle-neck capsules, size 00 with a narrow chamber at the bottom (Polysciences) and inserted the legs vertically. Polymerization was carried out without shaking at $55^{\circ} \mathrm{C}$ for two $\mathrm{d}$ in $\mathrm{N}_{2}$. (This was done in a Modular Incubator Chamber, Billups-Rothenberg). Ultrathin sections $(\sim 50 \mathrm{~nm})$ were cut using a diamond knife (Diatome) with a MTX ultramicrotome (Boeckeler) and placed on 200 mesh nickel grids. The sections were examined in a JEM-1210 transmission electron microscope (JEOL USA) at $120 \mathrm{kV}$.
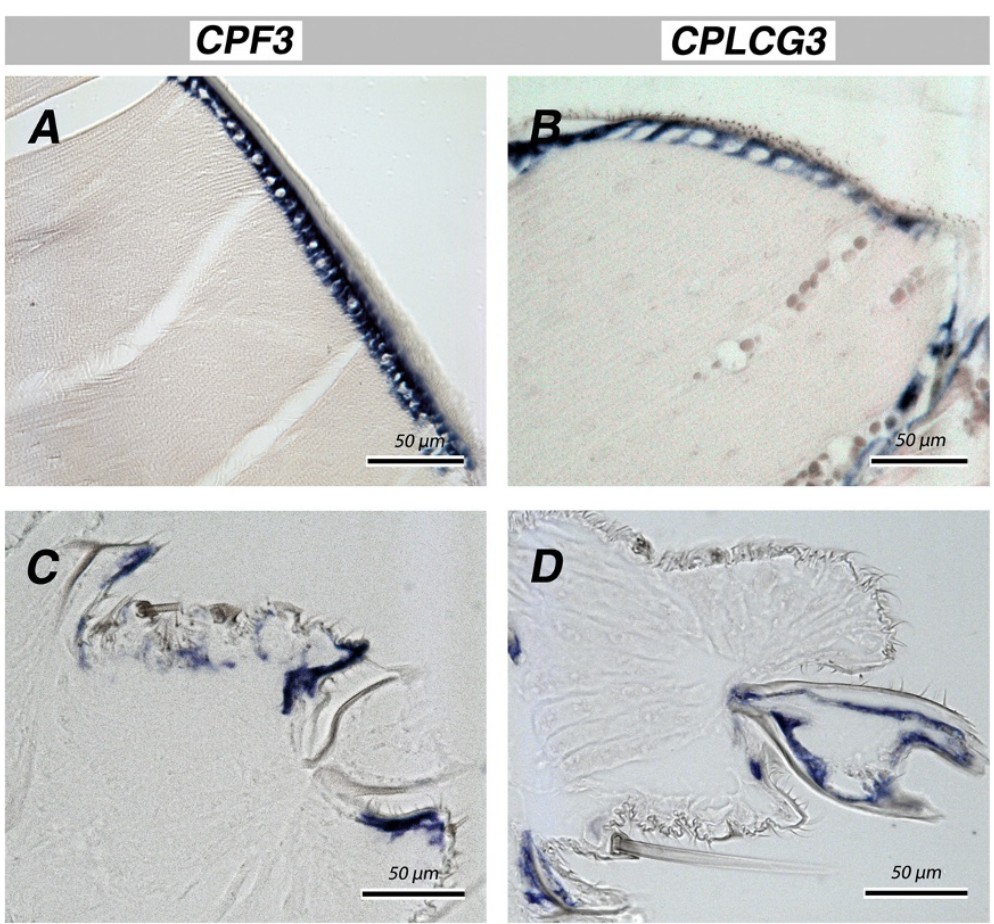

Figure 4 In situ hybridization to other regions. Hybridization to muscle insertion zones for both CPF3 (A) and CPLCG3 (B). (A) maleP24, (B) female P24 (C, D) Hybridization to genitalia, (C) adult female 12 hr, (D) male P24. 
The images were captured with an XR41C Bottom-Mount CCD Camera (Advanced Microscopy Techniques).

\section{EM Immunocytochemistry}

We used results from in situ hybridization and RTqPCR $[3,4]$ to select the tissues for EM immunolocalization. Thus, the distribution of CPF3 and CPLCG3/4 was evaluated in legs of pharate adults and 1-d, and 8-d-old adults. Antibodies were diluted in $0.5 \mathrm{M} \mathrm{NaCl}, 0.1 \% \mathrm{BSA}$, 0.05\% TWEEN 20 and 5\% FBS as follows: CPF3 (1:500), CPLCG3/4 (1:20,000), and the colloidal-gold conjugated secondary antibodies (1:50). As a negative control, sections were incubated with the pre-immune serum from the same animals from which the GenScript antibodies had been obtained. All treatments were carried out in $30 \mu \mathrm{l}$ drops placed on parafilm in a covered Petri dish $(150 \times 15 \mathrm{~mm})$. The grids with sections were incubated face down on drops of PBS (5 min), block solution (5\% BSA, $2 \%$ goat serum in PBS) (30 min), primary antibody (overnight), PBS (10 min, 3X), block solution (30 min), secondary antibody (1h), PBS (10 min, $2 \mathrm{X})$ and deionized water $(10 \mathrm{~min}, 2 \mathrm{X})$. All steps were performed at room temperature except the incubation of the primary antibody/pre-immune serum that was performed at $4^{\circ} \mathrm{C}$.

\section{Results and discussion}

\section{Transcript abundance}

Temporal expression of these four genes had been monitored previously $[3,4]$. In order to be able to compare transcript levels on the same preparations of cDNA, we repeated these measurements with fresh material (Figure 2). While both pairs of genes had transcripts when the adult cuticle is being laid down, the two CPLCG genes have maximal transcript levels later than the $C P F$ genes and their transcript levels were lower. The data had the same temporal pattern as our earlier studies, but there in young adults, CPLCG4 was similar to CPLCG3 [4] and CPF4 was lower than CPF3
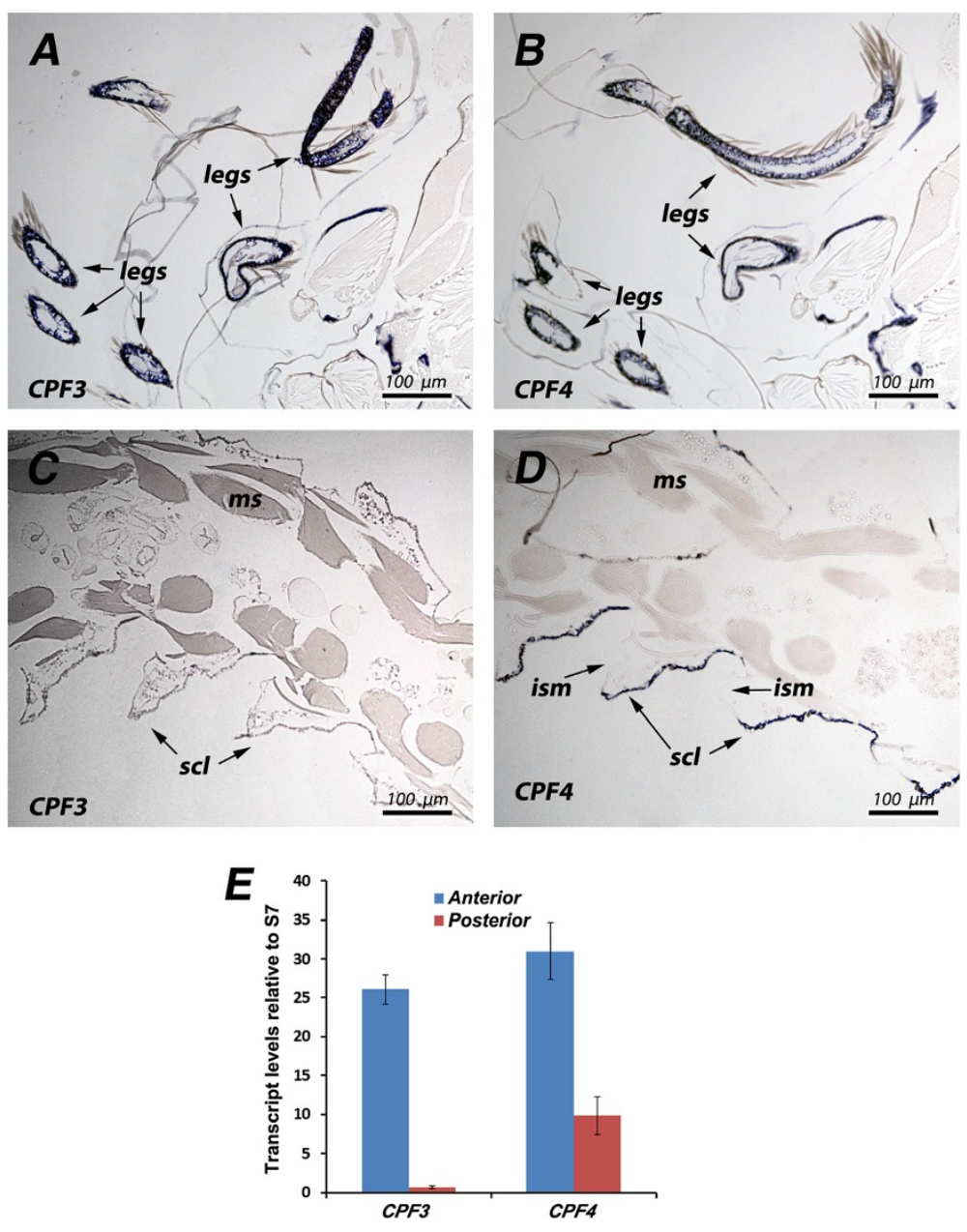

Figure 5 Comparison of CPF3 and CPF4 expression in male pharate adults (P24). Probes for both genes hybridize equally to the limbs (A, B). However, only CPF4 hybridizes to abdominal sclerites (D), a location not seen with CPF3 (C). (E) RT-qPCR of CPF3 and CPF4 in pharate adult anterior (head and thorax) and posterior (abdomen) at P24. Standard errors are shown. ism, intersegmental membrane; scl, sclerites; ms, muscle. 
[3]. Adult eclosion in An. gambiae is gated to occur after the dark period begins. Some pharate adults at P24 will be only a few hours away from eclosion, others will wait much longer. The animals we were comparing between our published work and this analysis were kept under different photoperiods and collected at different times of the day, so quantitative differences in relative transcript levels are not surprising, and indeed we observed this difference. (see Additional file 2).

\section{Transcript localization}

Results from in situ hybridization are in accord with the mRNA temporal patterns, but reveal that the situation is more complex. The CPF3 probe hybridized best in pharate adults (P24) (Figure 3A, C), while CPLCG3 was most abundant in young adults (Figure $3 \mathrm{~F}$ ). Nonetheless, for some specimens, there was strong hybridization at the other stage (Figure 3D). Transcripts were also detected in other tissues. Transcripts from all four genes were present in the thorax where muscle and cuticle came in contact (muscle insertion zones) (examples in Figure 4A, B). In pharate adults of both sexes, all four genes had transcripts in the genitalia (examples in Figure 4C, D). None of the probes were detected in the eyes, with the exception of artifactual labeling of the acellular lens, a common problem with RNA probes which also frequently react with the old, acellular, pupal cuticle [11].

While CPF3 and CPF4 had identical patterns of hybridization to appendages (Figure $5 \mathrm{~A}, \mathrm{~B}$ ), only the probe for CPF4 reacted with the general epidermis of the pharate adult abdomen, and here, just the sclerites and not intersegmental membranes (Figure 5C, D). We carried out RT-qPCR for CPF3 and CPF4 on anterior (head and thorax) and posterior (abdomen) regions. Transcript levels were higher in the abdomen for CPF4 than they were for CPF3 (Figure $5 \mathrm{E}$ ), a nice confirmation of the in situ results.

The presence of CPLCG3 and CPLCG4 in limbs is in accord with their role in insecticide resistance because those are the areas of the body that come in contact with insecticides that had been applied to surfaces. Likewise, the presence of $C P F 3$ in the genitalia might reflect a role in mating. But, the fact that the two CPLCGs were present in genitalia and both CPFs were present in limbs, complicates a simplistic story. Rather these results seem to suggest that CPF3/4 and CPLCG3/4 play complementary roles in formation of appendage cuticles.

\section{Western blot}

Western blot analysis of crude protein extracts from adult legs and bodies detected a strong band for CPF3 and CPLCG3/4 around 37 and $31 \mathrm{kDa}$, respectively (Figure 6). A faint band around 74kDa was also detected for CPF3. The calculated molecular masses of the secreted proteins were: $12.49 \mathrm{kDa}$ for CPF3 and $10.75 \mathrm{kDa}$ for CPLCG3/4 (based on the average masses of the two proteins). Thus, it is possible that CPF3 forms trimers and a smaller amount of hexamers, because bands three- and six-times larger than the inferred molecular weight were detected. A trimer for CPLCG3, or CPLCG4 or a combination is also possible. Another contributing factor may be that the apparent different molecular masses reflect the previously described abnormal electrophoretic mobility of many cuticular proteins [13]. Unfortunately, the similar MWs of related CPLCG

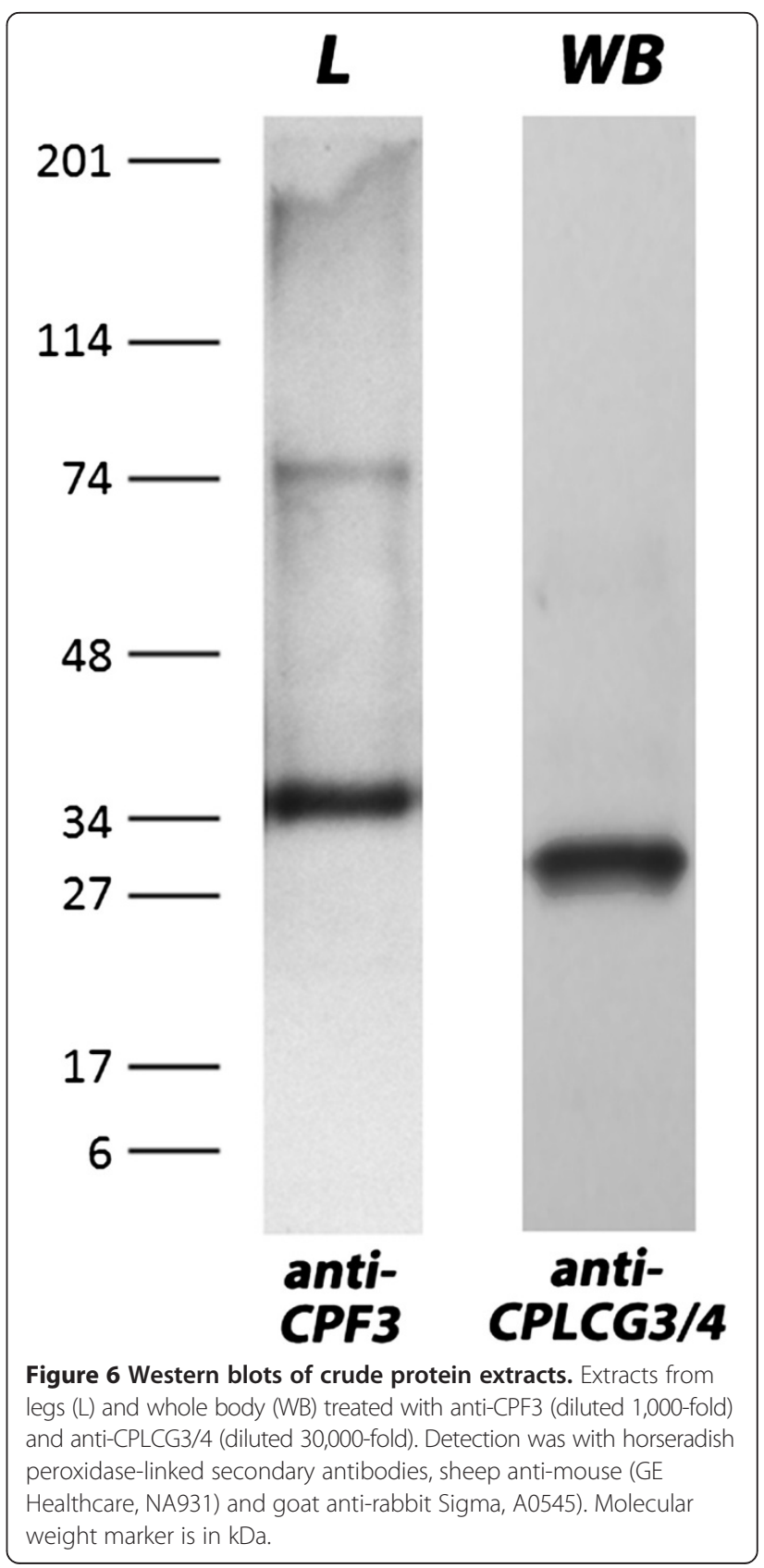




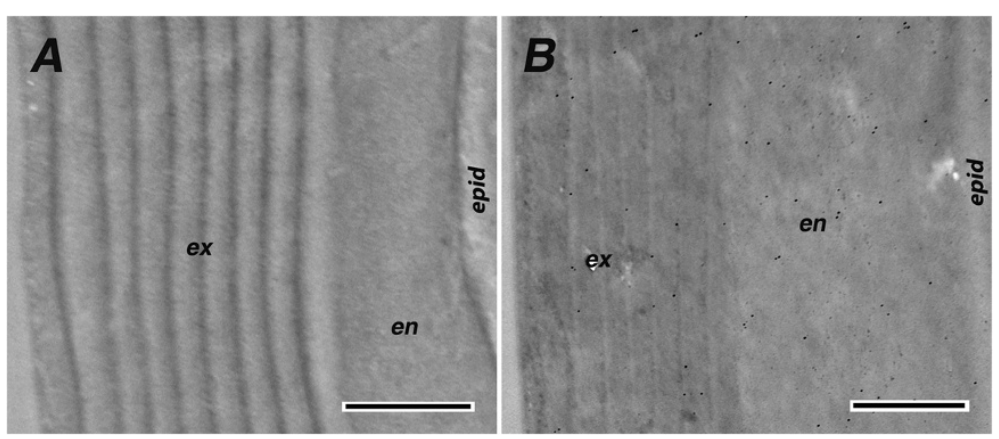

Figure 7 Sections of 1-d-old mosquito legs treated with the pre-immune serum. Preimmune serum was collected from the same animals used to raise the anti-CPF3 (A) and the anti-CPLCG3/4 (B). Secondary antibodies were anti-mouse and anti-rabbit, respectively. ex, exocuticle; en, endocuticle; epid, epidermis. Scale bar=500 nm.
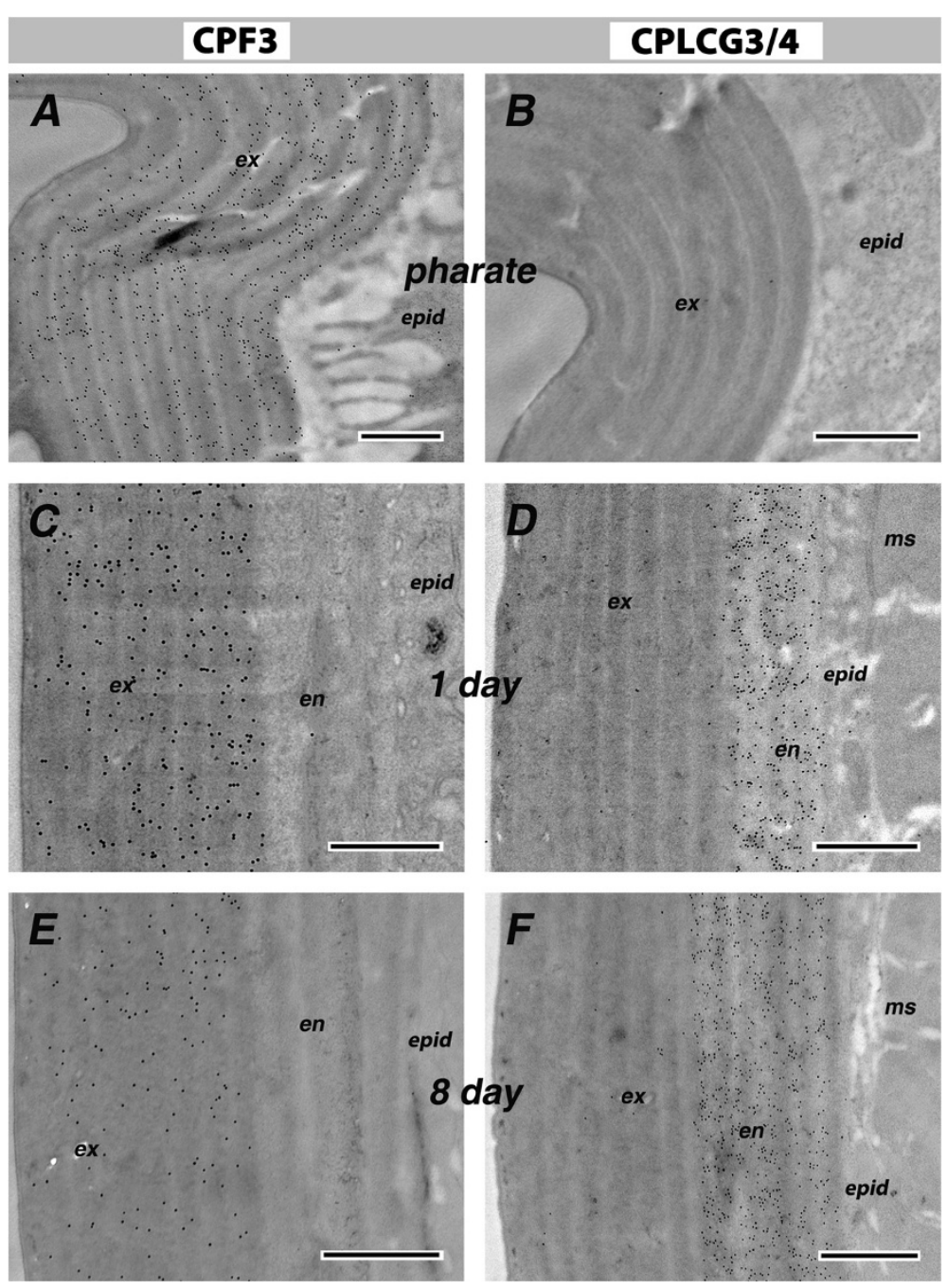

Figure 8 Ultrastructural immunolocalization in leg cuticles. Primary antibodies were raised against CPF3 (left panels) and CPLCG3/4 (right panels). (A, B) P24 pharate adults; (C, D) 1-d-old adults; (E, F) 8-d-old adults. Anti-CPF3 and Anti-CPLCG3/4 were detected by secondary antibodies, conjugated to 10 and $5 \mathrm{~nm}$ gold particles, respectively. ex, exocuticle; en, endocuticle; epid, epidermis; ms, muscle. Scale bar=500 nm. Apparent size of gold particles is dependent on focal plane. 
proteins (Additional file 4) means the single band found in the Western Blots does not guarantee that the antibody is solely recognizing CPLCG3/4.

\section{Immunocytochemistry}

First we verified that the secondary antibodies that had been conjugated to colloidal gold did not, in themselves, react with components of the cuticle. We detected only an occasional dispersed gold particle when these secondary antibodies were tested on sections that had been incubated with the appropriate pre-immune serum (Figure 7).

CPF3 expression was detected throughout the cuticle at high levels in animals fixed at $24 \mathrm{~h}$ after pupation (pharate adults). At this stage, only the epicuticle and pre-ecdysial exocuticle are present (Figure 8A). After eclosion, four morphologically distinct cuticular layers can be identified (epicuticle, exo- and endo-cuticle and assembly zone). Here too, in 1-d-old adults, CPF3 was detected only in exocuticle (Figure $8 \mathrm{C}$ ). Even in the oldest mosquitoes examined (8-d-old adults), CPF3 was restricted to exocuticle even though at this age, the endocuticle also appears lamellar (Figure 8E).

Togawa et al. [3] used the same assay that had been used to demonstrate chitin-binding by members of the CPR family $[14,15]$ to learn if the CPF family had chitin binding properties. Neither recombinant CPF1 nor CPF3 bound chitin, although CPR21 tested at the same time did. Based on this result and the aggregation observed with the recombinant protein, they speculated that CPF3 might be located in the epicuticle, the layer of the insect
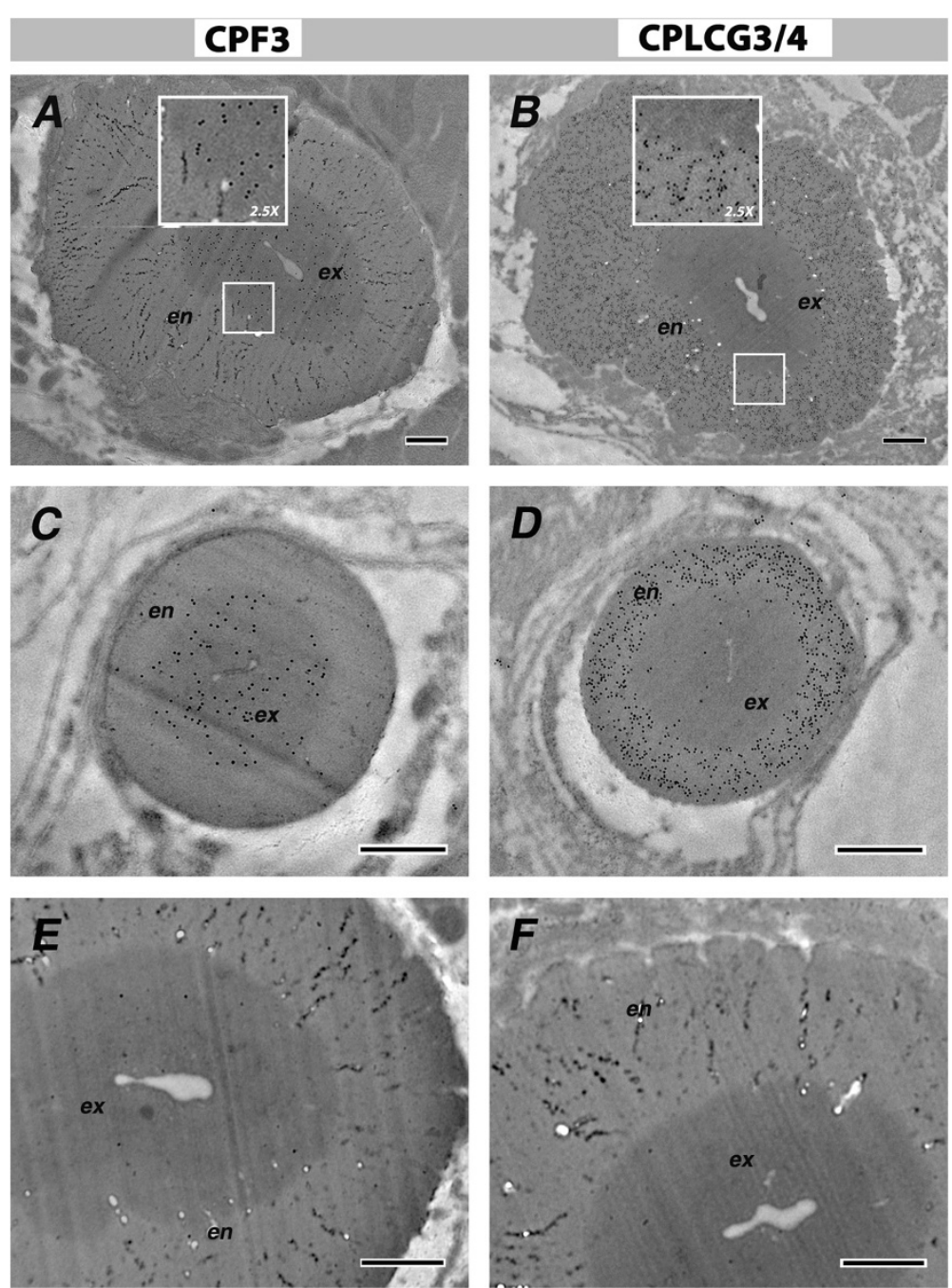

Figure 9 Ultrastructural immunolocalization in leg apodemes of 1-d-old mosquitoes. CPF3 (left panels) and CPLCG3/4 (right panels) are shown in the flexor tibiae apodeme cuticle (A, B); and extensor tibiae apodeme (C, D). (E, F) Control sections treated with the appropriate pre-immune serum; note the granulated structures in the endocuticle. Sections were incubated with goat anti-mouse (A, C, E) or with goat anti-rabbit (B, D, F) secondary antibodies conjugated to 10- and 5-nm gold particles, respectively. ex, exocuticle; en, endocuticle Scale $b a r=500 \mathrm{~nm}$. 
cuticle that lacks in chitin [3]. A homology model of CPF3 indicated the presence of a pocket in a $\beta$-barrel structure [7]. Unlike a somewhat similar homology model for some CPR proteins [16], chitin could not be computationally docked in this pocket. Cassone et al. [5] had suggested that CPF3 might serve as a courtship modulator, thus explaining its different transcript levels in $\mathrm{M}$ and $\mathrm{S}$ incipient species. Papandreou et al. [7] thus computationally tested a Drosophila sex pheromone, 7(Z), 11(Z)-heptacosadiene and learned that it could be docked in the CPF3 pocket. Lacking any Anopheles pheromone to test, all this really revealed was that hydrocarbons could fit. Our data reveal that CPF3 is localized only in the exocuticle and thus is not well positioned to present a contact pheromone. So perhaps, CPF3 is just one of those cuticular proteins that fill spaces between the chitin binding proteins as suggested in a model of Andersen [17]. But an exciting possibility is that CPF3 holds hydrocarbons in the cuticle and its higher levels (if high transcript=high protein) in $\mathrm{M}$ than $\mathrm{S}$, correlates provocatively with the greater desiccation resistance found in adults of the $\mathrm{M}$ form [18]. Indeed, the large differences in transcript levels between $\mathrm{M}$ and $\mathrm{S}$ fit better with a model where they are used for something less subtle than pheromone presentation, especially in a species where, to date, there is no evidence for a courtship pheromone.

CPLCG3/4 was not detected in the cuticle of pharate adults (Figure 8B). Rather, in contrast to the findings with CPF3, protein was found only in the endocuticle of both 1-d-old and 8-d-old adults (Figure 8D, F). CPF3 and CPLCG3/4 were also detected in the exocuticle and endocuticle, respectively, of An. gambiae flexor and extensor tibiae apodemes (Figure 9).

The predominant presence of CPLCG3 and CPLCG4 mRNAs in limbs and the abundance of the protein in limb cuticle correlates nicely with the $>2$-fold increased abundance of their transcript in pyrethroid resistance An. gambiae [9]. Furthermore, an earlier study found, with both microarray and RT-qPCR, that the CPLCG3 ortholog in An. stephensi was among the small number of transcripts that were more abundant in the insecticide-resistant form of that species [8]. Given that adult mosquitoes contact insecticides through their limbs, this would be a perfect site to have more abundant cuticular proteins underwriting a thicker cuticle. Wood et al. [19] have shown that pyrethroid resistant An. funestus do indeed have a thicker cuticle on their legs than sensitive forms and suggested that this might slow down penetration of the insecticide allowing more time for detoxification mechanisms to act. Higher levels of transcripts of CPs have been correlated with insecticide resistance in studies in other insects [20-22]. The older literature has examples of decreased penetration of labeled insecticides in resistant insects $[23,24]$.

\section{Conclusions}

These data provide additional information on why $A n$. gambiae devotes almost $2 \%$ of its protein coding genes to structural cuticular proteins. Although CPF3/4 and CPLCG3/4 have overlapping periods of transcript expression and predominant transcript localization in the same tissues, appendages, their proteins are completely segregated in the cuticle. CPF3 is restricted to exocuticle and CPLCG3/4 is only found in the endocuticle. The presence of CPLCG3/4 in limbs correlates nicely with its role in insecticide resistance. The higher level of CPF3 transcripts in $\mathrm{M}$ than in $\mathrm{S}$ incipient species was once suggested to play a role in pheromone display. We now know that wing beat frequency is the major player in mate recognition [25], and while contact pheromones have not been ruled out, the localization of CPF3 in exo- and not epi-cuticle suggests that it is unlikely to be playing a role in mate recognition. But there remains a possibility that CPF3 contributes to the greater resistance to desiccation of the $\mathrm{M}$ form. The specific localization of CPs within the cuticle and the areas where CPF4 but not CPF3 probes hybridize in pharate adults are further indications that the multiplicity of $\mathrm{CP}$ genes must be, at least in part, because they are serving specific, but in some cases, overlapping functions.

\section{Additional files}

\begin{abstract}
Additional file 1: DNA sequences and locations of primers and probes used for in situ hybridization. (A) Nucleic acid sequences of CPF3 and CPF4. (B) sequences of CPLCG3 and CPLCG4. Shown are in situ primers (bold) and in situ probes (gray highlight), start (green) and stop (red) codons; CPLCG4 primers are in orange. Two different probes were used for CPLCG3, with primers indicated in black bold (for CPLCG3) and blue bold for CPLCG3-EA. Reverse primers are shown as the complement on the coding strand.
\end{abstract}

Additional file 2: Effect of photophase on transcript levels from P24 animals. Female mosquitoes $24 \mathrm{~h}$ after pupation were harvested at different times relative to the start of the dark period. (AZT is Arbitrary Zeitgeber Time with time 0 the start of lights on.) For each CP transcript, means with different letters are statistically significant $(p \leq .05)$. (A) CPF3 and CPF4. (B) CPLCG3 and CPLCG4. (C) RpS7 threshold cycles for the data shown above. There are no significant differences between groups. RT-qPCR was performed with Bio-Rad's CFX Connect Real Time System. We used three groups of three animals each for cDNA preparation for each condition. All values show mean \pm SEM. All reactions were carried out in triplicate (technical replicates) in a $15 \mu \mathrm{l}$ reaction

containing $3.75 \mu \mathrm{l}$ of $1 / 100$ diluted CDNAs (equivalent to starting with 5.6ng of total RNA), $250 \mathrm{nM}$ of each primer, and $7.5 \mu \mathrm{l}$ SsoAdvanced SYBR $^{\oplus}$ Green Supermix (Bio-Rad). PCR conditions were $95^{\circ} \mathrm{C}$ for $2 \mathrm{~min}$ followed by 40 cycles of $95^{\circ} \mathrm{C}$ for $10 \mathrm{~s}$ and $57^{\circ} \mathrm{C}$ for $30 \mathrm{~s}$.

Additional file 3: Primers used for RT-qPCR.

Additional file 4: Potential off-target effects. Each of the 14 aa peptides used to generate antibodies was submitted to BLAST (blastp) against the Anopheles gambiae proteome (PEST) and alignments produced are shown along with MWs and published data on transcript abundance obtained with RT-qPCR $[3,4]$. With the exception of CPLCG5, it is unlikely that other CPS would be recognized by the antibodies. CPLCG1 is expressed in many tissues including scales [11], so we know that it is 
not recognized by the antibody raised against CPLCG3/4. The RT-qPCR data come from measurements made with different conditions for animal rearing and transcript levels than those used for other data in this paper. Data for transcripts compared in the Table are based on the same conditions.

\section{Competing interests}

The authors declare that they have no competing interests.

\section{Authors' contributions}

LV and JHW conceived and designed the study, analyzed the data and drafted the MS. LV performed the immunological components. TWR carried out the RT-qPCR and helped with in situ hybridization. All authors read and approved the final version of the MS

\section{Acknowledgements}

We thank Dr. Scott Cornman and Dr. Hitoshi Tsujimoto for designing and making some of the in situ probes and Chase Naples for help with processing some in situs. Dr. Reben Rahman helped with the Western blots. We also thank Dr. Mark R. Brown and Anne Robertson for maintaining the mosquito facility from which these animals were obtained, Dr. Michael Strand for access to his Leica photomicroscope and Dr. Yihong Zhou for comments on the MS. Dr. John Shields from the UGA Center for Ultrastructural Research provided training in preparing EM sections. Special thanks are due to Mary B. Ard of the UGA Electron Microscopy Laboratory in the College of Veterinary Medicine for training and consulting with the EM component. An anonymous reviewer provided insightful suggestions. This research was funded by a grant from the U.S. National Institutes of Health R01Al55624.

Received: 4 December 2013 Accepted: 9 January 2014

Published: 15 January 2014

\section{References}

1. Willis JH: Structural cuticular proteins from arthropods: annotation, nomenclature, and sequence characteristics in the genomics era. Insect Biochem Mol Biol 2010, 40:189-204.

2. Willis JH, Papandreou NC, Iconomidou VA, Hamodrakas SJ: Cuticular proteins. In Insect Molecular Biology and Biochemistry. Edited by Gilbert LI. Chapel Hill (NC): Academic; 2012:134-166.

3. Togawa T, Dunn WA, Emmons AC, Willis JH: CPF and CPFL, two related gene families encoding cuticular proteins of Anopheles gambiae and other insects. Insect Biochem Mol Biol 2007, 37:675-688.

4. Cornman RS, Willis $\mathrm{JH}$ : Annotation and analysis of low-complexity protein families of Anopheles gambiae that are associated with cuticle. Insect $\mathrm{Mol}$ Biol 2009, 18:607-622.

5. Cassone BJ, Mouline K, Hahn MW, White BJ, Pombi M, Simard F, Costantini C, Besansky NJ: Differential gene expression in incipient species of Anopheles gambiae. Mol Ecol 2008, 17:2491-2504.

6. della Torre A, Fanello C, Akogbeto M, Dossou-Yovo J, Favia G, Petrarca V Coluzzi M: Molecular evidence of incipient speciation within Anopheles gambiae s.s. in West Africa. Insect Mol Biol 2001, 10:9-18.

7. Papandreou NC, Iconomidou VA, Willis JH, Hamodrakas SJ: A possible structure model of members of the CPF family of cuticular proteins implicating binding to components other than chitin. J Insect Physiol 2010, 56:1420-1426.

8. Vontas J, David JP, Nikou D, Hemingway J, Christophides GK, Louis C, Ranson H: Transcriptional analysis of insecticide resistance in Anopheles stephensi using cross-species microarray hybridization. Insect Mol Biol 2007, 16:315-324.

9. Awolola TS, Oduola OA, Strode C, Koekemoer LL, Brooke B, Ranson H: Evidence of multiple pyrethroid resistance mechanisms in the malaria vector Anopheles gambiae sensu stricto from Nigeria. Trans $R$ Soc Trop Med Hyg 2009, 103:1139-1145.

10. Ranson H, N'Guessan R, Lines J, Moiroux N, Nkuni Z, Corbel V: Pyrethroid resistance in African anopheline mosquitoes: what are the implications for malaria control? Trends Parasitol 2011, 27:91-98.

11. Vannini L, Dunn WA, Reed TW, Willis JH: Changes in transcript abundance for cuticular proteins and other genes three hours after a blood meal in Anopheles gambiae. Insect Biochem Mol Biol 2014, 44:33-43.
12. Lan $\mathrm{Q}$, Massey RJ: Subcellular localization of mosquito sterol carrier protein-2 and sterol carrier protein-x. J Lipid Res 2004, 45:1468-1474.

13. Cox DL, Willis $\mathrm{JH}$ : Analysis of the cuticular proteins of Hyalophora cecropia with two dimensional electrophoresis. Insect Biochem 1987, 17:457-468.

14. Rebers JE, Willis JH: A conserved domain in arthropod cuticular proteins binds chitin. Insect Biochem Mol Biol 2001, 31:1083-1093.

15. Togawa T, Nakato H, Izumi S: Analysis of the chitin recognition mechanism of cuticle proteins from the soft cuticle of the silkworm, Bombyx mori. Insect Biochem Mol Biol 2004, 34:1059-1067.

16. Iconomidou VA, Willis JH, Hamodrakas SJ: Unique features of the structural model of 'hard' cuticle proteins: implications for chitin-protein interactions and cross-linking in cuticle. Insect Biochem Mol Biol 2005, 35:553-560.

17. Andersen SO: Studies on proteins in post-ecdysial nymphal cuticle of locust, Locusta migratoria, and cockroach, Blaberus craniifer. Insect Biochem Mol Biol 2000, 30:569-577.

18. Lee $Y$, Meneses CR, Fofana A, Lanzaro GC: Desiccation resistance among subpopulations of Anopheles gambiae s.s. from Selinkenyi, Mali. J Med Entomol 2009, 46:316-320.

19. Wood O, Hanrahan S, Coetzee M, Koekemoer L, Brooke B: Cuticle thickening associated with pyrethroid resistance in the major malaria vector Anopheles funestus. Parasit Vectors 2010, 3:67.

20. Mamidala P, Wijeratne AJ, Wijeratne S, Kornacker K, Sudhamalla B, Rivera-Vega LJ, Hoelmer A, Meulia T, Jones SC, Mittapalli O: RNA-Seq and molecular docking reveal multi-level pesticide resistance in the bed bug. BMC Genomics 2012, 13:6.

21. Zhu F, Gujar H, Gordon JR, Haynes KF, Potter MF, Palli SR: Bed bugs evolved unique adaptive strategy to resist pyrethroid insecticides. Sci Rep 2013, 3:1456.

22. Koganemaru R, Miller DM, Adelman ZN: Robust cuticular penetration resistance in the common bed bug (Cimex lectularius L.) correlates with increased steady-state transcript levels of CPR-type cuticle protein genes Pestic Biochem Physiol 2013, 106:190-197.

23. DeVries DH, Georghiou GP: Decreased nerve sensitivity and decreased cuticular penetration as mechanisms of resistance to pyrethroids in (1R)-trans-permethrin-selected strain of the housefly. Pestic Biochem Physiol 1981, 15:231-234

24. Wu D, Scharf ME, Neal JJ, Suiter DR, Bennett GW: Mechanisms of fenvalerate resistance in the German cockroach, Blattella germanica (L). Pestic Biochem Physiol 1998, 61:53-62.

25. Pennetier C, Warren B, Dabire KR, Russel IJ, Gibson G: "Singing on the wing" as a mechanism for species recognition in the malarial mosquito Anopheles gambiae. Curr Biol 2010, 20:131-136.

doi:10.1186/1756-3305-7-24

Cite this article as: Vannini et al:: Temporal and spatial expression of cuticular proteins of Anopheles gambiae implicated in insecticide resistance or differentiation of $\mathrm{M} / \mathrm{S}$ incipient species. Parasites \& Vectors 2014 7:24.

\section{Submit your next manuscript to BioMed Central and take full advantage of:}

- Convenient online submission

- Thorough peer review

- No space constraints or color figure charges

- Immediate publication on acceptance

- Inclusion in PubMed, CAS, Scopus and Google Scholar

- Research which is freely available for redistribution 